\title{
Application of a Furan-Containing Polymer/Fullerene System to Photolithography
}

\author{
Yusuke Tajima, ${ }^{* * *}$ Yoshihiko TezuKa, ${ }^{*}$ Tadahiro IshII, ${ }^{* \dagger}$ and Kazuo TaKeuchI** \\ * Department of Applied Chemistry, Faculty of Science, Science University of Tokyo, \\ 1-3 Kagurazaka, Shinjuku-ku, Tokyo 162, Japan \\ ** The Institute of Physical and Chemical Research (RIKEN), \\ 2-1 Hirosawa, Wako, Saitama 351-01, Japan
}

(Received May 29, 1997)

\begin{abstract}
A furan-containing polymer turned to a gel and then solidified in 1,1,2,2-tetrachloroethane solution in the presence of fullerene $\mathrm{C}_{60}$ under visible light irradiation. The reaction mechanism involved the polycondensation of furan units via singlet oxygen generated from the excited triplet state of $\mathrm{C}_{60}$. This photo-crosslinking process was applied to a photoresist having sensitivity in the visible region. The first example was demonstrated for the micron size photolithographic patterning using the furan-containing polymer/fullerene system.

KEY WORDS Fullerene / Furan-Containing Polymer / Singlet Oxygen / Photooxygenation / Gelation / Photoresist / Photolithography /
\end{abstract}

Fullerenes have been introduced into polymers by various methods such as the $[1,3]$-dipole cycloaddition to azido-substituted polystyrene ${ }^{1}$ or the addition to aminocontaining polymers. ${ }^{2-4}$ The introduction of fullerenes into polymers through photochemical methods is especially useful because it can be applied to the radiationcuring of resins or photoresists. The $[2+2]$-cycloaddition with substituted cyclohexenones ${ }^{5}$ and the addition through photoinduced electron transfer with triethylamine $^{6}$ are reported examples of the photochemical reaction of fullerene. Fullerene has been used as a useful sensitizer of recently discovered photofunctional polymers such as a photoconductive ${ }^{7}$ or photorefractive polymer. ${ }^{8}$ We have reported that fullerene $\mathrm{C}_{60}$ can be used as an effective photo-gelling agent for furan-containing polymers. ${ }^{9}$ Since $\mathrm{C}_{60}$ absorbs light over the visible region, the photo-gelling should proceed by visible light irradiation. This can be applied to a photoresist having sensitivity in the visible region. In this report, we investigated the mechanism of the photogelation process. We also demonstrate the first example of photolithographic patterning using the furan-containing polymer/fullerene system.

\section{EXPERIMENTAL}

\section{Materials}

Fullerene $\mathrm{C}_{60}$ was purchased from the Term Co. and was of the $>99.98 \%$ grade. Poly(2-hydroxyethylmethacrylate) (PHMA) was synthesized by the free radical polymerization of 2-hydroxyethylmethacrylate (30 $\mathrm{wt} \%$ ) in $300 \mathrm{ml}$ of 2-propanol using an $\alpha, \alpha^{\prime}$-azobis(isobutyronitrile) (AIBN) initiator $\left(1.0 \times 10^{-3} \mathrm{wt} \%\right)$ at $80^{\circ} \mathrm{C}$ for $12 \mathrm{~h}$ under a $\mathrm{N}_{2}$ atmosphere. The polymer was obtained as a white powder at $88 \%$ yield after being purified by reprecipitation from hexane and dried under vacuum. The PHMA was then treated with 2-furoic chloride by dropping $15 \mathrm{~g}$ of 2-furoic chloride into $20 \mathrm{ml}$ of pyridine solution containing $20 \mathrm{~g}$ of PHMA while stirring for $6 \mathrm{~h}$ at $30^{\circ} \mathrm{C}$. The product was purified by reprecipit- ation from hexane and dried under vacuum, yielding $18 \mathrm{~g}$ (51\% yield) of poly(2-furoic acid [2-(methacryloyl-oxy)ethyl] ester) (PFMA) as a white powder (see Scheme 1). The furan unit was introduced into the side chain at ca. $90 \%$ as determined by ${ }^{1} \mathrm{H}$ NMR and FT-IR spectra. From the gel permeation chromatography (GPC) analysis, the $M_{n}$ and $M_{w} / M_{n}$ were determined to be $5.77 \times 10^{4}$ and 3.5 , respectively. ${ }^{1} \mathrm{H}$ NMR of PFMA $\left(\mathrm{C}_{2} \mathrm{D}_{2} \mathrm{Cl}_{4}\right) \delta 8.84(2 \mathrm{H}, \mathrm{d}, J=4.4 \mathrm{~Hz}), 8.45(1 \mathrm{H}, \mathrm{m}), 7.97$ $(2 \mathrm{H}, \mathrm{m}), 7.63(2 \mathrm{H}, \mathrm{d}, J=11.7 \mathrm{~Hz}), 7.23(2 \mathrm{H}, \mathrm{s}), 6.53(2 \mathrm{H}$, s), $6.02(2 \mathrm{H}, \mathrm{s}), 4.42(3 \mathrm{H}$, broad $), 4.20(3 \mathrm{H}$, broad $), 1.90$ ( $2 \mathrm{H}$, broad), $1.80(2 \mathrm{H}$, broad $), 1.26(2 \mathrm{H}$, broad $), 1.00$, $0.87(2 \mathrm{H}, \mathrm{m}) ;{ }^{13} \mathrm{C}$ NMR of PFMA $\left(\mathrm{C}_{2} \mathrm{D}_{2} \mathrm{Cl}_{4}, 400 \mathrm{MHz}\right)$ $\delta 178.42,177.65,161.74,159.78,159.75,148.52,148.24$, $147.14,146.02,145.56,145.48,142.55,128.61,120.35$, $120.26,113.74,113.71,64.30,63.47,55.74,46.51,46.20$, $24.26,20.26,18.45$.

\section{Irradiation Method}

PFMA and $\mathrm{C}_{60}$ were dissolved in distilled 1,1,2,2tetrachloroethane (TCE) in the dark at $23^{\circ} \mathrm{C}$. The solution was then irradiated through a Pyrex filter using a $150 \mathrm{~W}$ xenon arc lamp as the light source.

\section{Gelation Method}

The reaction between PFMA and $\mathrm{C}_{60}$ was carried out as follows. Fifteen $\mathrm{mg}$ of $\mathrm{C}_{60}$ (>99.98\%, Term Co.) was added to $50 \mathrm{ml}$ of distilled TCE containing $500 \mathrm{mg}$ of PFMA stirred at $23^{\circ} \mathrm{C}$. The solution was then irradiated using a $150 \mathrm{~W}$ xenon arc lamp with its broad spectrum output filtered using a Pyrex filter. As the reaction proceeded, the color of the solution changed from the

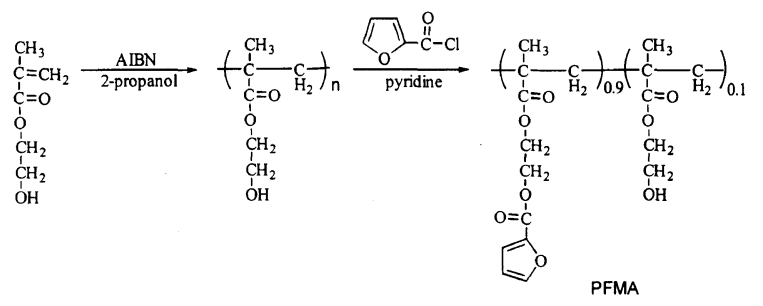

Scheme 1.

† To whom correspondence should be addressed. 


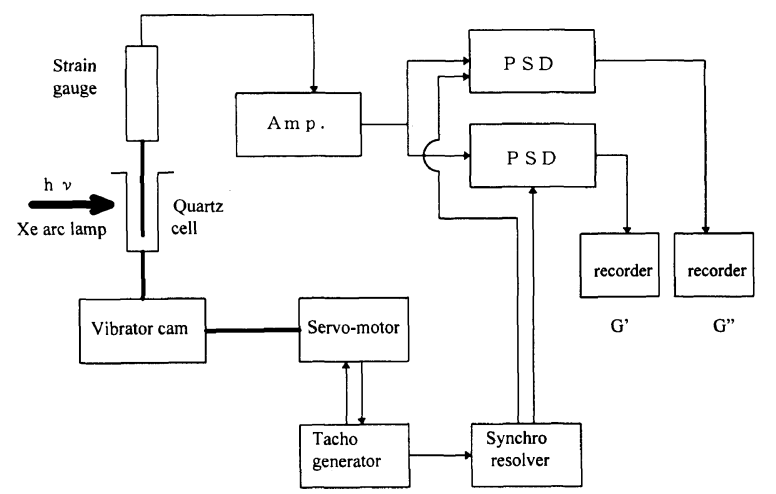

Figure 1. Schematic diagram of viscoelastorecorder (VER).

light purple of $\mathrm{C}_{60}$ to a dark red after $5 \mathrm{~min}$, and the viscosity of the solution increased. When it became a gel after $10 \mathrm{~h}$, it shrank by $c a .10 \%$ in volume relative to the initial solution. The gel completely solidified upon further irradiation.

\section{Measurements}

Differential scanning calorimetry (DSC) analysis of a PFMA $/ \mathrm{C}_{60}$ mixture and its gel was conducted using a Rigaku Thermoflex TG8110 by increasing the temperature at $5^{\circ} \mathrm{C} \mathrm{min}^{-1}$ under an argon atmosphere. The ${ }^{1} \mathrm{H}$ NMR spectra were recorded on a JEOL JMN- $\alpha-400$ (400 $\mathrm{MHz}$ ) instrument. Tetramethylsilane (TMS) was used as the internal reference in 1,1,2,2-tetrachloroethane- $d_{2}$. GPC analysis was performed in a Shimadzu LC-6A equipped with a RI detector (Shodex SE-51) using a Shodex column (AD-80M/S). The IR spectra were obtained using a Shimadzu FT-IR-4200 spectrophotometer. The UV-Vis spectra were obtained with a Hitachi UV-2000 spectrophotometer using a quartz cell with a $1-\mathrm{cm}$ light path. In situ measurement of the dynamic viscoelasticity during gelation of the PFMA- $\mathrm{C}_{60}$ solution during irradiation was performed using a viscoelastorecorder (VER) with a quartz cell. ${ }^{10}$ A schematic diagram of the VER is shown in Figure 1. A $1.0-\mathrm{ml}$ portion of the sample solution was placed in a cell of which both sides were made of two parallel quartz plates. A metal inner plate was then immersed in the solution. The cell was vertically oscillated by a vibrator cam at a frequency of $1 \mathrm{~Hz}$ so that the sample was sheared between the inner plate and the quartz walls of the cell. The force acting on the inner plate was detected by a strain gauge. The output signal from the strain gauge was amplified and led to the phase sensitive detectors, from which both the real and imaginary parts of the rigidity moduli, $G^{\prime}$ and $G^{\prime \prime}$, were derived and recorded as a function of time. The gap width between the inner plate and the quartz walls of the cell was $1 \mathrm{~mm}$ and the shear strain was 0.002 .

\section{RESULTS AND DISCUSSION}

The photographs in Figure 2 demonstrate the changing of the PFMA- $\mathrm{C}_{60}$ solution into a gel. A TCE solution containing $1000 \mathrm{~g} \mathrm{dm}^{-3}$ (about $5 \mathrm{~mol} \mathrm{dm}^{-3}$ in monomer units) of PFMA and $0.072 \mathrm{~g} \mathrm{dm}^{-3}\left(1 \times 10^{-3} \mathrm{~mol} \mathrm{dm}^{-3}\right)$ of $\mathrm{C}_{60}$ was placed in a Petri dish and irradiated from the top of the solution (a). The color of the solution changed from the initial purple of $\mathrm{C}_{60}$ to a dark brown (a)

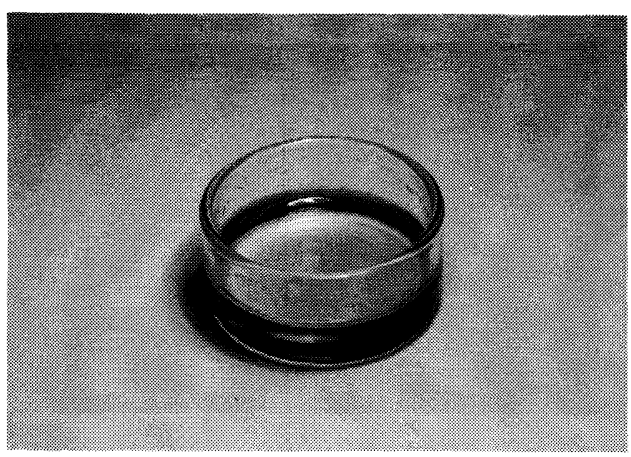

(b)

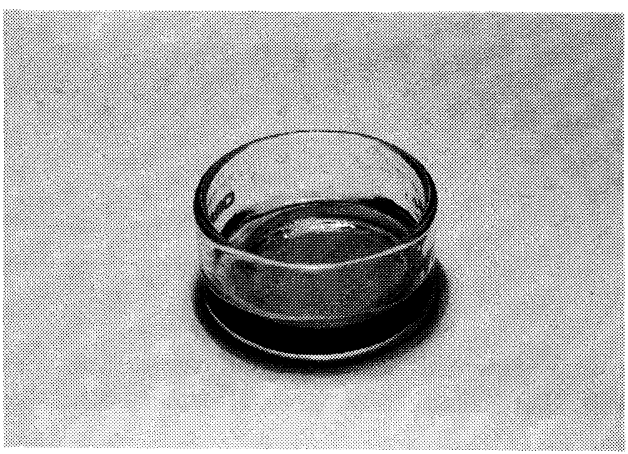

Figure 2. Photographs of TCE solution containing $1000 \mathrm{~g} \mathrm{dm}^{-3}$ of PFMA and $1 \times 10^{-4} \mathrm{~mol} \mathrm{dm}^{-3}$ of $\mathrm{C}_{60}$ before irradiation (a) and after $48 \mathrm{~h}$ visible light irradiation $(\mathrm{b})$.

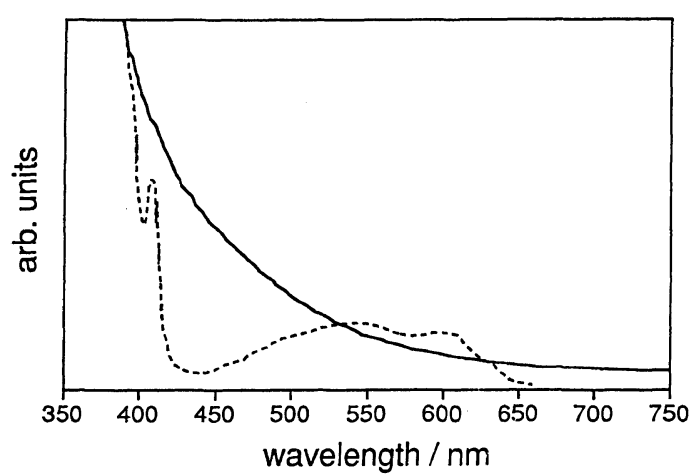

Figure 3. Absorption spectra of a PFMA- $\mathrm{C}_{60}$ solution in TCE before $(--)$ and after (-) irradiation for $2 \mathrm{~h}$.

after $5 \mathrm{~min}$. As the reaction proceeded, the viscosity of the solution increased and it turned to a gel after $10 \mathrm{~h}$ (b). The volume of the gel was $c a .90 \%$ of the initial volume of the solution. The gel was completely solidified further irradiation.

Figure 3 shows the absorption spectra of the PFMA$\mathrm{C}_{60}$ solution before and after the irradiation. The spectrum before irradiation showed a prominent absorption band centered at $420 \mathrm{~nm}$ and a broad band around $650 \mathrm{~nm}$ both of which are characteristic of the absorption spectrum of $\mathrm{C}_{60}$. Upon irradiation, the band at $420 \mathrm{~nm}$ decreased and a broad band appeared around $500 \mathrm{~nm}$. As the reaction proceeded, the band around $420 \mathrm{~nm}$ disappeared while the broad band ranging from 450 to $700 \mathrm{~nm}$ increased monotonically. Figure 4 shows the DSC curves of the PFMA-C 60 gel and a PFMA $/ \mathrm{C}_{60}$ mixture. The PFMA- $\mathrm{C}_{60}$ gel showed a new peak around $330^{\circ} \mathrm{C}$, suggesting that a new chemical bond was formed by visible light irradiation.

In order to investigate the gelation process of the 


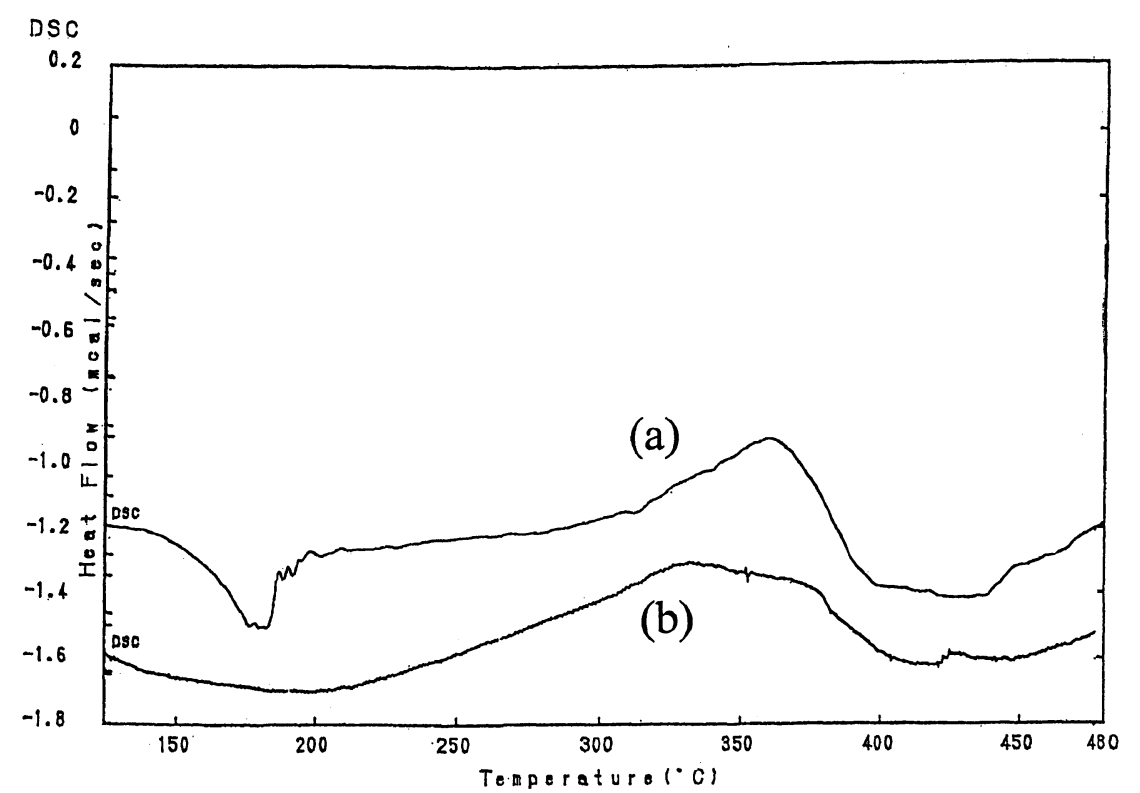

Figure 4. Differential scanning calorimetry traces for the PFMA- $\mathrm{C}_{60}$ before irradiation (a) and after irradiation for $24 \mathrm{~h}$ (b) (scan rate, $\left.10^{\circ} \mathrm{C} \min ^{-1}\right)$.

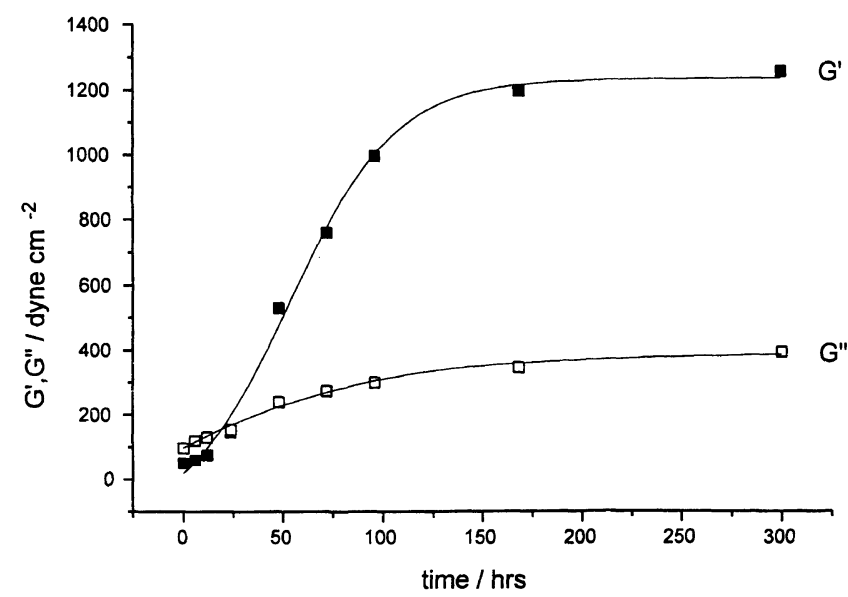

Figure 5. Dynamic rigidity modulus $G^{\prime}(\square)$ and loss modulus $G^{\prime \prime}(\square)$ during gelation of PFMA-C 60 solution with light irradiation.

PFMA-C $_{60}$ solution, we have measured the dynamic viscoelasticity using VER during the irradiation. Figure 5 shows variations in the storage modulus, $G^{\prime}$, and the loss modulus, $G^{\prime \prime}$, with the irradiation time for a TCE solution containing $1000 \mathrm{~g} \mathrm{dm}^{-3}$ of PFMA and $1 \times 10^{-3}$ moldm ${ }^{-3}$ of $\mathrm{C}_{60}$. The intersection of the $G^{\prime}$ and $G^{\prime \prime}$ curves corresponds to the gelation point. The rapid increase in $G^{\prime}$ passing $G^{\prime \prime}$ indicates that the PFMA-C 60 solution changed into the gel after $24 \mathrm{~h}$. Both the $G^{\prime}$ and $G^{\prime \prime}$ values consistently increased with the concentration of $\mathrm{C}_{60}$, and the swelling ratio decreased with the increase in the $\mathrm{C}_{60}$ concentration (Figure 6). These results suggest that $\mathrm{C}_{60}$ works to create the closslinking points which construct the polymer network. Unfortunately, any change in the NMR spectrum of $\mathrm{C}_{60}$ could not be detected in both the ${ }^{1} \mathrm{H}$ and ${ }^{13} \mathrm{C}$ NMR measurements, because the concentration of $\mathrm{C}_{60}$ was quite low compared to that of PFMA.

In our previous paper, we have reported that the main products of the photochemical reaction of methyl 1018

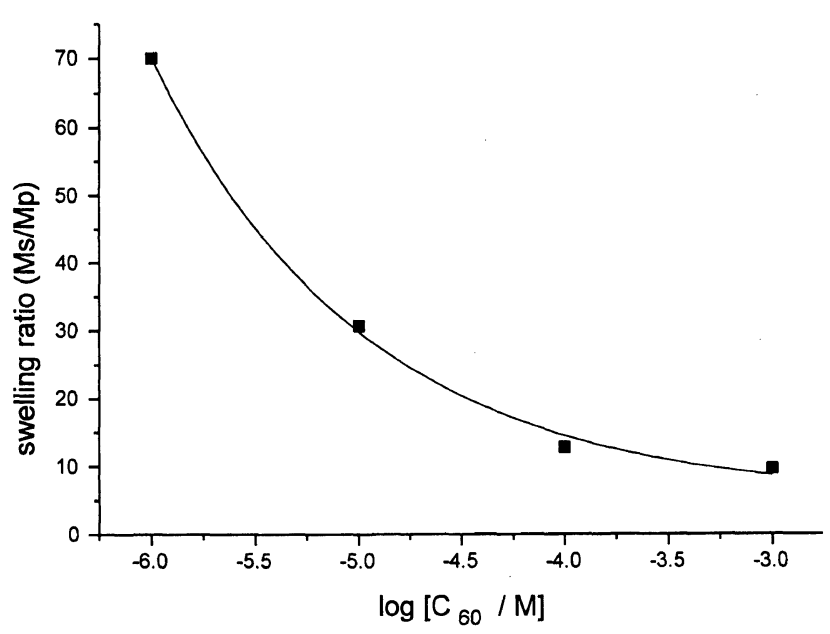

Figure 6. Swelling ratio of PFMA-C 60 gel in TCE as function of $\mathrm{C}_{60}$ concentration. The swelling ratio is defined as the mass of absorbed solvent (TEC) per mass of dried polymer disk $\left(M_{\mathrm{s}} / M_{\mathrm{p}}\right)$.

2-furoate (MFA) and $\mathrm{C}_{60}$ in the presence of oxygen were a furan resin and $\mathrm{C}_{60} \mathrm{O}_{n}(n=1-10) .{ }^{11}$ We concluded that the reaction mechanism yielding the furan resin was the polycondensation of MFA via oxygenation by singlet oxygen generated with the function of $\mathrm{C}_{60}$ as a photosensitizer. We considered that the endperoxides of MFA underwent polycondensation to form the conjugated polymer, namely, the furan resin, as shown in Scheme 2. The gelation of the PFMA- $\mathrm{C}_{60}$ solution can be considered to proceed in the same way. First, the photo-excited $\mathrm{C}_{60}$ generates singlet oxygen, which migrates to the furan units of PFMA and oxygenates them. The oxygenated furan units turn to the endoperoxides and undergo a thermal polycondensation reaction. The network was constructed as a result of the intermolecular binding between the furan units on different PFMA chains.

In order to verify this proposed gelation mechanism, the irradiation was carried out in the presence of

Polym. J., Vol. 29, No. 12, 1997 


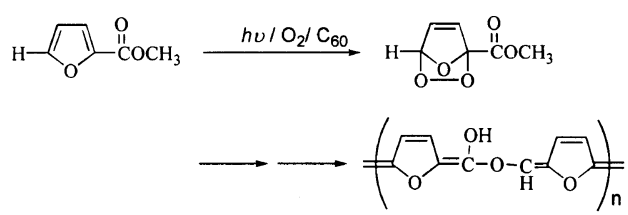

Scheme 2.

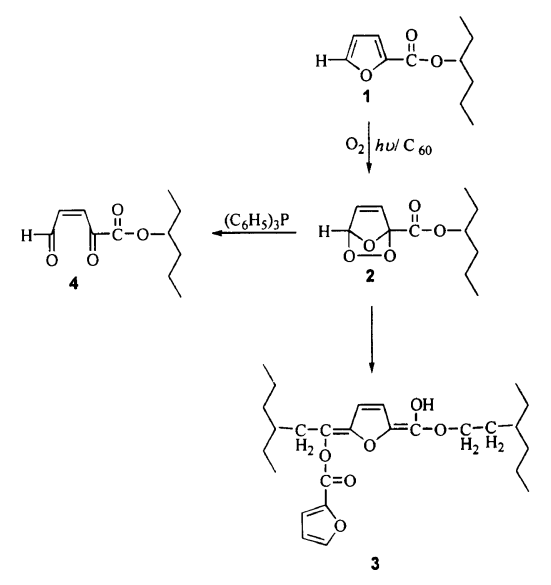

Scheme 3.

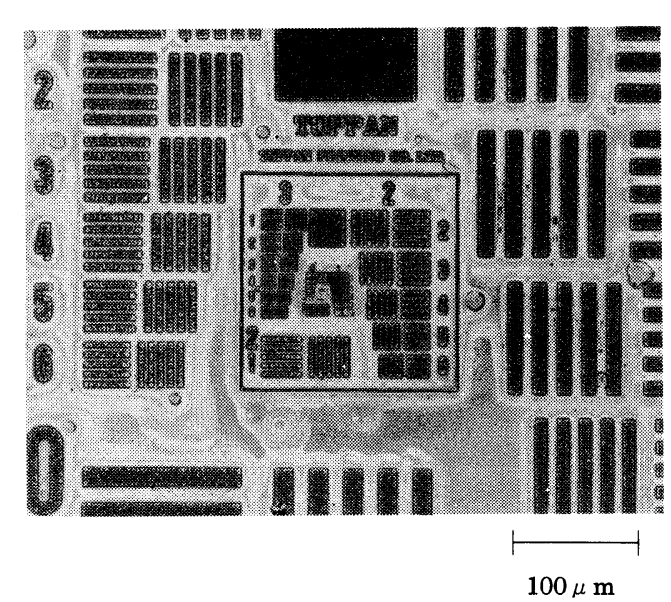

Figure 7. Photograph of a fine pattern image using PFMA- $\mathrm{C}_{60}$ \{thickness, $1.5 \mu \mathrm{m}$; exposure dose, $1 \mathrm{~J} \mathrm{~cm}^{-2}$ (>530 nm); development, dipping for $1 \mathrm{~min}$ using TCE $\}$.

1,3-diphenyl-i-benzofuran (DBF) or triphenylphosphine (TPP). The DBF works as a quencher of singlet oxygen and the TPP acts as a reducing agent for the furan peroxide. ${ }^{12}$ The addition of a small amount of these reagents inhibited the increase in $G^{\prime}$ and $G^{\prime \prime}$ of the PFMA- $\mathrm{C}_{60}$ solution during the visible irradiation. These results clearly support the proposed mechanism.

As a conclusion, the gellation mechanism is summarized in Scheme 3. The furan units of the PFMA were oxidized by singlet oxygen and undergo polymerization to construct the polymer network. The brown color of the PFMA- $\mathrm{C}_{60}$ gel is ascribed to the conjugated structure of the polycondensates of the furan units. ${ }^{13}$
Finally, we applied the PFMA- $\mathrm{C}_{60}$ system to a photoresist. A cast film of PFMA- $\mathrm{C}_{60}$ formed on a glass substrate was exposed to a $400 \mathrm{~W}$ high pressure mercury lamp equipped with a Pyrex filter through a photomask. After $1 \mathrm{~min}$, the pattern was developed with TCE and dried at $80^{\circ} \mathrm{C}$ in a clean oven. A fine pattern image of a micron size was obtained as shown in Figure 7. This is the first example of the application of fullerene to photolithography. Since the PFMA- $\mathrm{C}_{60}$ system has a high sensitivity to visible light and its reaction is not inhibited by oxygen, it has advantages over the usual negative type resist using free radicals. Especially, it would be suitable for such use as a pigment-dispersed resist which can not appreciably transmit ultraviolet light. $^{8}$ In addition, this system guarantees excellent cost performance because it requires only a small quantity of expensive fullerene.

\section{CONCLUSIONS}

We demonstrated that fullerene $\mathrm{C}_{60}$ works as a sensitizer involving singlet oxygen for the photocrosslinking of furan-containing polymers. The furancontaining polymer/fullerene system can be applied to negative type photolithography forming micron size patterning with high sensitivity in the visible region. A high efficiency is also expected in the use of fullerene as a sensitizer of radiation curable resins.

Acknowledgment. We would like to thank Mr. J. Onoe and Dr. K. Yasufuku of the Institute of Physical and Chemical Research (RIKEN) for their helpful discussions.

\section{REFERENCES}

1. E. T. Samulski, J. M. DeSimone, M. O. Hunt, Y. Z. Menceloglu, R. C. Jarnagin, G. A. York, K.B. Labat, and H. Wang, Chem Mater., 4, 1153 (1992).

2. K. E. Geckeler and A. Hirsch J. Am. Chem. Soc., 115, 3850 (1993)

3. N. Manalova, I. Rashkov, F. Beguin, and H. V. Damme, J. Chem. Soc., Chem. Commun., 1725 (1993).

4. A. O. Patil, G. W. Schriver, B. Carstensen, and R. D. Lundberg, Polym. Bull., 30, 187 (1993).

5. C. J. Hawker, Macromolecules, 27, 4836 (1994).

6. K. I. Guhr, M. D. Greaves, and V. M. Rotello, J. Am. Chem. Soc., 116, 5997 (1994).

7. Y. Wang, Nature, 356, 585 (1992).

8. S. M. Silence, C. A. Walsh, J. C. Scott, and W. E. Moerner, Appl. Phys. Lett., 61, 2967 (1992).

9. Y. Tajima, Y. Tezuka, H. Yajima, T. Ishii, and K. Takeuchi, Polym. Commun., in press.

10. E. Fukuda and M. Kaibara, Thrombosis Res., 8 (Suppl. II), 49, (1976).

11. Y. Tajima, H. Arai, Y. Tezuka, T. Ishii, and K. Takeuchi, Fullerene Sci. Tech., in press.

12. H-J. Schumacher and J. Stauff, Die Chemie, 55, 341 (1942).

13. N. Galego and A. Gandini, J. Polym. Sci., Polym. Chem. Ed., 15, 1027 (1977).

14. Y. Tajima, H. Masuko, and N. Bessho, Japan Print Associate, 118, 32 (1994). 